\title{
Quality assurance of the Greek UV Network: preliminary results from the pilot phase operation
}

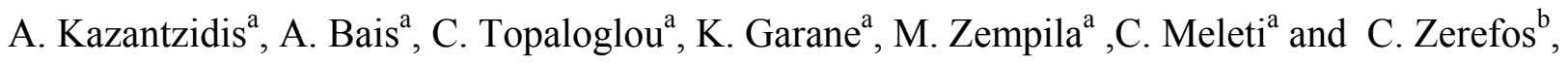 \\ ${ }^{a}$ Laboratory of Atmospheric Physics, Campus Box 149, Aristotle University of Thessaloniki, 54124, \\ Thessaloniki, Greece
}

${ }^{\mathrm{b}}$ Laboratory of Atmospheric Environment, Foundation for Biomedical Research, Academy of Athens

\begin{abstract}
The stratospheric ozone depletion during the last two decades, the increase of UV-B irradiance levels at the ground and the possible impact on the biosphere has led scientists to develop and use instruments of high accuracy for UV measurements.

During the last two years, 9 UV stations have been established in different environments in Greece and Cyprus, with the aim to establish a long-term monitoring network. The instruments of the network (NILU-UV multichannel filter radiometers) can provide measurements of irradiance in the UV and the visible part of the solar spectrum.

In this study, first results from the calibration measurements and the quality assurance procedures are presented. The stability of the maximum of spectral response and the full width at half maximum was measured within $0.5 \mathrm{~nm}$. Lamp tests were performed and downward drifts up to $40 \%$ in UVA channel sensitivity were observed. Calibration factors derived from lamp measurements could provide measurements of UV dose rate and total ozone with quite good agreement when compared with standard ultraviolet instruments.
\end{abstract}

Keywords: ultraviolet irradiance, multichannel filter radiometer

\section{INTRODUCTION}

The spatial and temporal variability of ultraviolet (UV) irradiance reaching the ground due to clouds, total ozone, aerosol properties and surface albedo has been discussed in detail in scientific literature ${ }^{1,2,3,4}$. Although satellite-derived estimations of UV irradiance could be used to establish a global UV climatology, the weakness to account correctly for aerosol and ozone in the boundary layer and the disadvantage to provide only one measurement per day lead to overestimation of UV irradiance by more than $15 \%$ in polluted sites ${ }^{5,6,7}$.

The ozone layer depletion and the resultant enhancement of UV irradiance reaching the ground, in combination with the consequences on the ecosystem induced by overexposure to ultraviolet radiation, stimulated the scientific community to establish monitoring programs of solar ultraviolet radiation in different countries ${ }^{8,9.10}$. Substantial efforts have also been made by scientists to produce long- and short-term forecasts of UV radiation levels ${ }^{11}$. Although spectroradiometers are considered to be the appropriate instruments to provide quality assured measurements of solar UV irradiance, they require a lot of attention and effort to maintain them. As a result, multichannel filter radiometers which have the advantages of easy calibration, little effort for maintenance and the appropriate methodology to derive several atmospheric (e.g ozone, cloud transmittance) and biologically effective quantities (e.g erythemal dose) have been extensively used in UV monitoring networks.

The results presented in this study refer to the multichannel filter radiometers of Greek UV Network. A short description of the network, the quality assurance procedures and the first results after 1.5 years of pilot operation will be discussed in the next paragraphs.

\section{DESCRIPTION OF THE NETWORK}


The network was designed to cover geographically Greece and Cyprus, comprising 8 satellite stations distributed at locations with different environments and a central station located at Thessaloniki, where a suite of spectral and broadband radiation and other related measurements are performed. One more radiometer is used as a traveling standard (table 1). The network provides online one-minute averages (with standard deviation) of channel irradiance from all stations through a newly designed algorithm. A series of products such as CIE-weighted UV dose rates, integrated UVA, UV-B and visible irradiances, cloud cover assessment and total ozone abundances are available based on the method described by A. Dahlback ${ }^{12}$.

\begin{tabular}{|c|c|c|c|c|}
\hline Site & Latitude $\left({ }^{\mathbf{0}} \mathbf{N}\right)$ & Longitude $\left({ }^{\mathbf{0}} \mathbf{E}\right)$ & Serial Number & $\begin{array}{c}\text { Start of } \\
\text { Measurements }\end{array}$ \\
\hline Thessaloniki & 40.5 & 23.0 & 04103 & $12 / 2004$ \\
\hline Nicosia (Cyprus) & 35.2 & 33.3 & 04104 & $05 / 2005$ \\
\hline Athens & 38.0 & 23.8 & 04105 & $12 / 2004$ \\
\hline Mytilene & 39.1 & 26.5 & 04107 & $01 / 2005$ \\
\hline Patra & 38.3 & 21.8 & 04108 & $10 / 2005$ \\
\hline Iraklio & 35.3 & 25.2 & 04109 & $03 / 2006$ \\
\hline Xanthi & 41.1 & 24.9 & 04110 & $09 / 2006$ \\
\hline Ioannina & 39.7 & 20.8 & 04111 & $10 / 2005$ \\
\hline Rhodes & 36.5 & 21.8 & 04114 & $05 / 2006$ \\
\hline
\end{tabular}

Table 1: Detailed information for the ground-based stations of the Greek UV Network

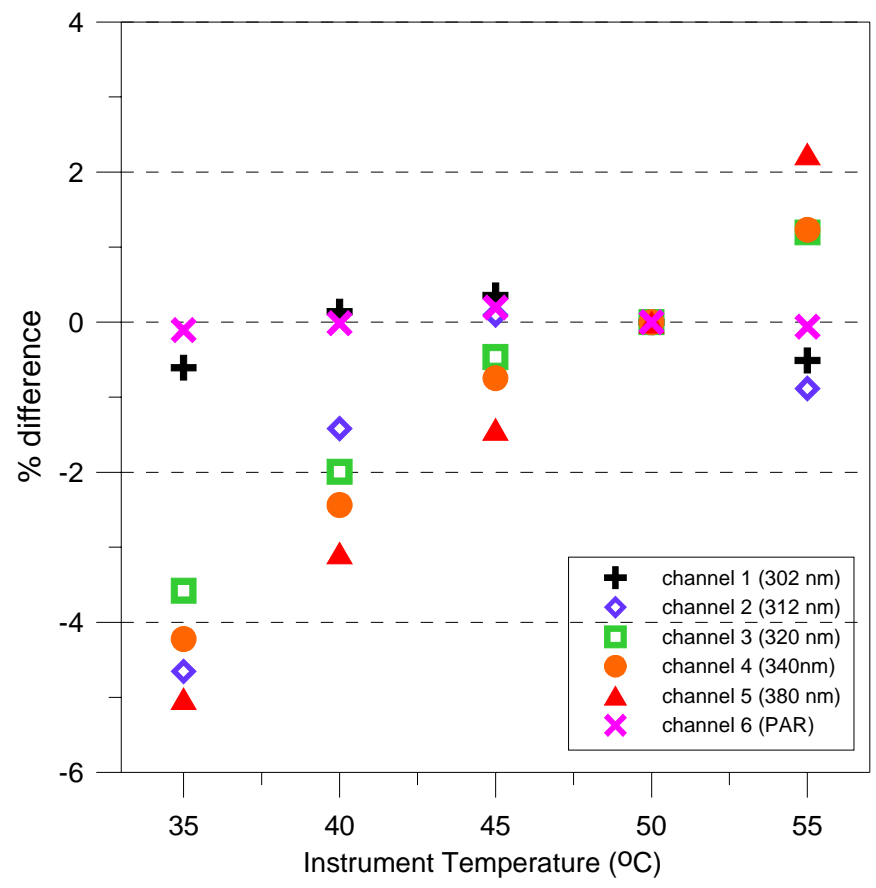

Figure 1. Sensitivity of a NILU-UV instrument in internal temperature variations.

NILU-UV multi-channel radiometers provide UV irradiance measurements at five wavelength bands centered at 302 , 312, 320, 340 and $380 \mathrm{~nm}$, with full width at half maximum (FWHM) of approximately $10 \mathrm{~nm}$. In addition, a sixth 
channel measures photosynthetic active radiation (PAR) between 400-700 nm. The technical details of the instrument are described in Hoiskar et al. ${ }^{13}$. The NILU-UV instruments are capable in maintaining their internal temperature to $50 \pm .01{ }^{\circ} \mathrm{C}$ throughout the year for the conditions of the 9 Greek stations. Occasionally, deviations of up to $\sim 3^{\circ} \mathrm{C}$ have been observed at the station in Cyprus, where the ambient temperature is generally higher. Figure 1 shows the expected error in irradiance at the 6 channels for various internal temperatures with respect to $50^{\circ} \mathrm{C}$. This error was derived by changing the stabilization temperature in one instrument while keeping a second one at normal operation. It appears that even for the observed occasional deviations of a few degrees in the stabilization temperature the effect in the irradiance measurements is negligible $(<1 \%)$. It also appears that the 300 and the PAR channels are almost insensitive to temperature variations.

\section{SPECTRAL AND COSINE RESPONSE CHARACTERIZATION}

Accurate measurement of spectral response characterization of filter radiometer channels appears necessary to gain results of high quality ${ }^{9}$. Although the manufacturer has performed these kinds of measurements, a new apparatus have been established at the Laboratory of Atmospheric Physics, in order to estimate also the cosine error of the instruments. The main parts of the apparatus are a 1000W Xe lamp and a grating double monochromator with prism predisperser. Typical measurements of spectral and cosine response for NILU-UV 05105 are presented in figure 2.
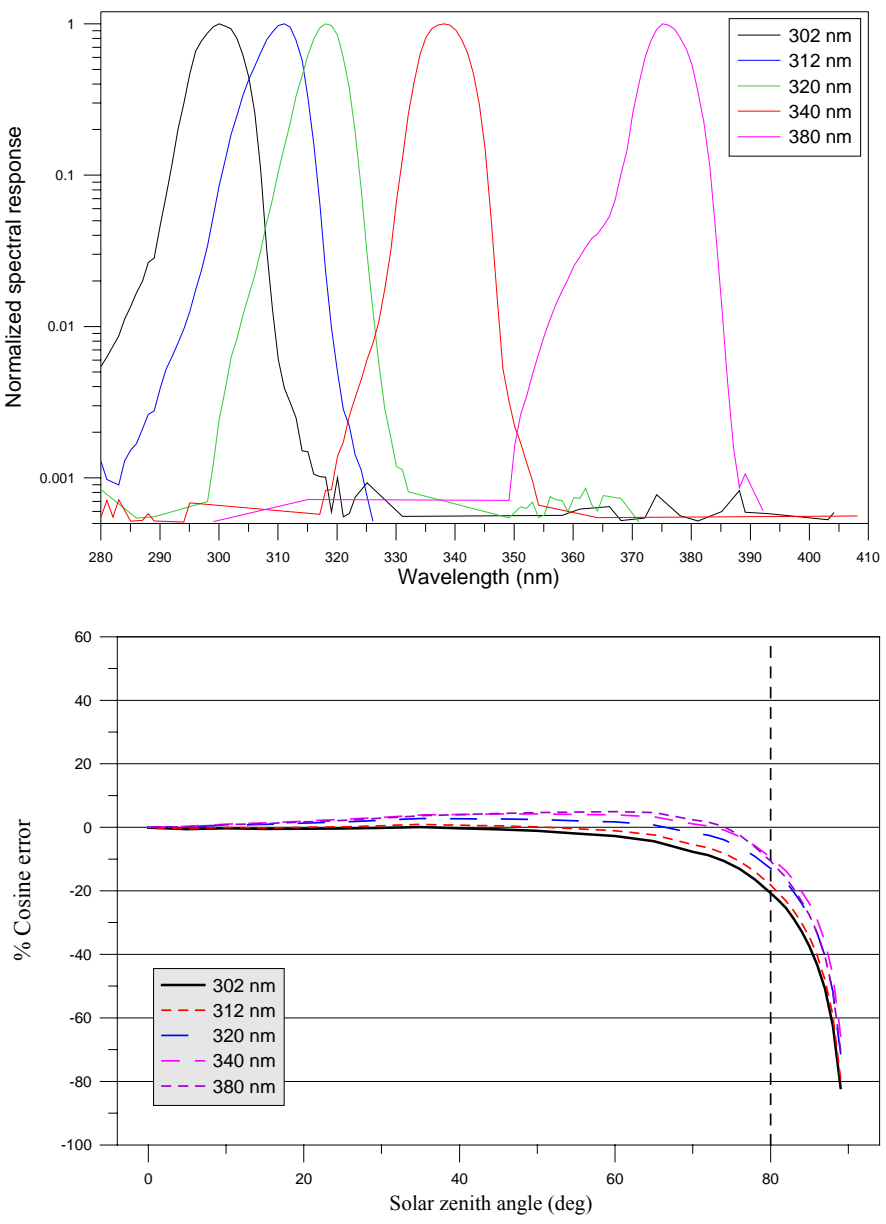

Figure 2. Normalized spectral response (upper panel) and cosine error (lower panel) for NILU-UV 04105 
The cosine error for all UV channels could be considered negligible for solar zenith angles less than 60 degrees. For low Sun conditions the cosine error at UV-B channels increases significantly and reaches $20 \%$ at 80 degrees, while it is less than $10 \%$ for the UV-A channels.

The spectral response of 2 NILU-UV instruments has been measured several times in the past three years in order to examine its stability during this time. Figure 3 shows the results of the deviations in the wavelength of the maximum response and in the Full Width at Half Maximum (FWHM) of each filter. It has been found that both the wavelength of maximum response and the FWHM are stable to within $\sim 0.5 \mathrm{~nm}$, since the instrument has been deployed at the station of Thessaloniki. For one instrument (04106), there are deviations between the measurements done at LAP with those provided initially by the manufacturer. According to Bernhard et al. ${ }^{9}$, this magnitude of uncertainty could lead to a $15 \%$ bias at $305 \mathrm{~nm}$ and $5 \%$ at $320 \mathrm{~nm}$, when comparing measurements of these channels with spectral measurements.
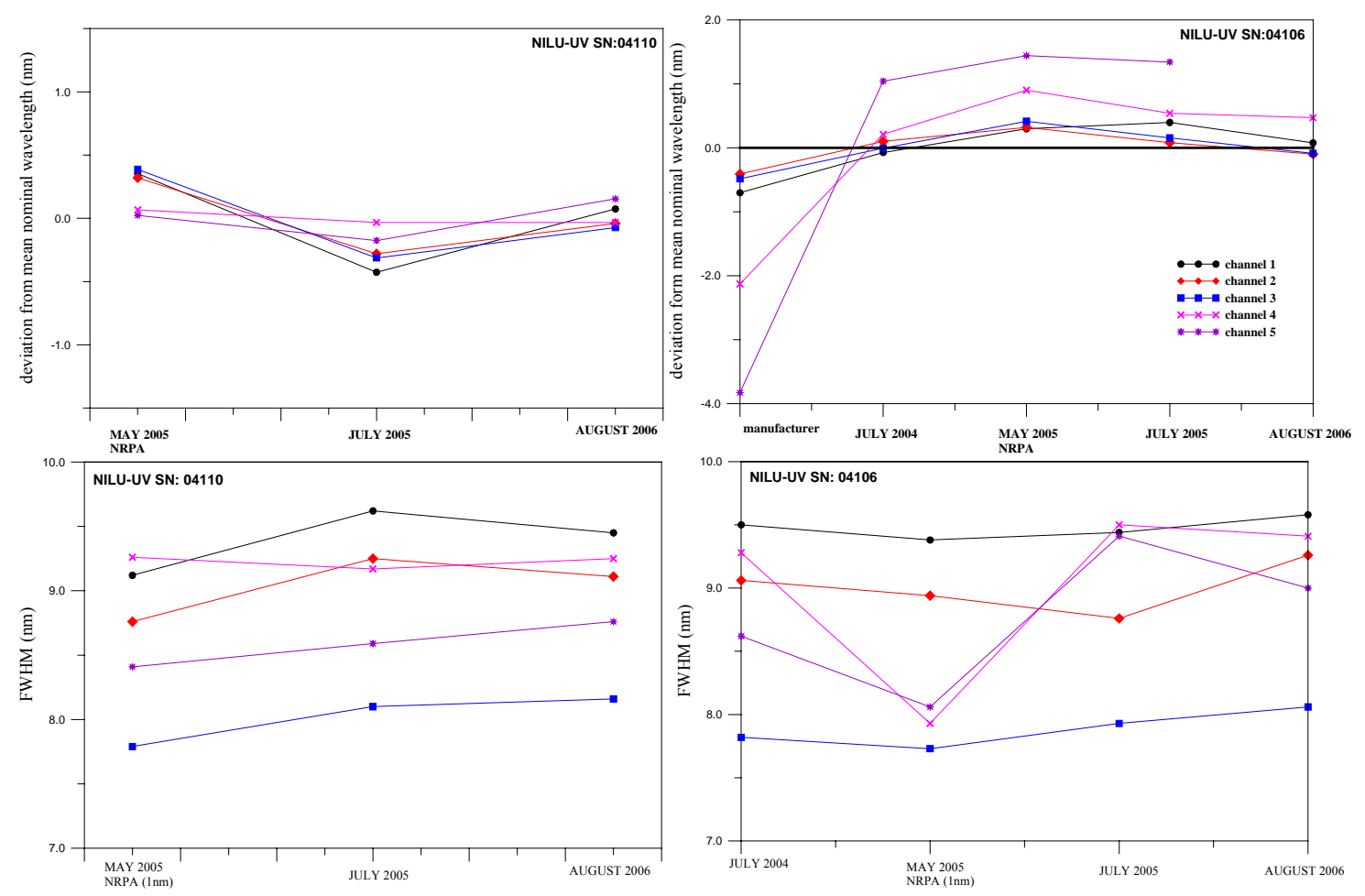

Figure 3. Variation with time in the wavelength of maximum spectral response of 2 NILU-UV instruments (upper panels) and in the FWHM of their filters (lower panels)

\section{CALIBRATION OF MULTI-CHANNEL FILTER RADIOMETERS}

\subsection{Solar comparison with spectroradiometers}

According to Dahlback ${ }^{12}$, the calibration factors $\mathrm{k}_{\mathrm{i}}$ for each NILU-UV channel could be derived from the equation:

$$
\mathrm{k}_{\mathrm{i}}=\frac{V_{\mathrm{i}}-D_{\mathrm{i}}}{\int_{0}^{\infty} R(\lambda) \mathrm{E}(\lambda) d \lambda}
$$


where:

$V_{i}$ and $D_{i}$ are the signal and the offset of channel $i$

$\mathrm{R}(\lambda)$ the normalized spectral response

$E(\lambda)$ the spectral irradiance measured by a spectroradiometer

The coefficients $\mathrm{k}_{\mathrm{i}}$ provide a simple relation between the raw counts of the radiometers and the measured irradiance of a spectroradiometer, while the stability of the coefficient is indicative for the channel stability. Since the end of 2004 , all instruments of the Greek UV Network are traceable with cosine corrected measurements from double Brewer \#086, located at Thessaloniki. As the Brewer spectroradiometer needs almost 8 minutes to perform a full scan (290-365 nm), we use for each channel the closest in time $1 \mathrm{~min}$ averages from NILU-UV instrument relative to the time of nominal wavelength measured from Brewer. The SHICrivm algorithm ${ }^{14}$ is applied to all spectra, to correct for wavelength shifts and non-natural spikes. In addition, all spectra are artificially extended to $400 \mathrm{~nm}$ by the algorithm, in order to calculate the calibration factors also for $380 \mathrm{~nm}$.

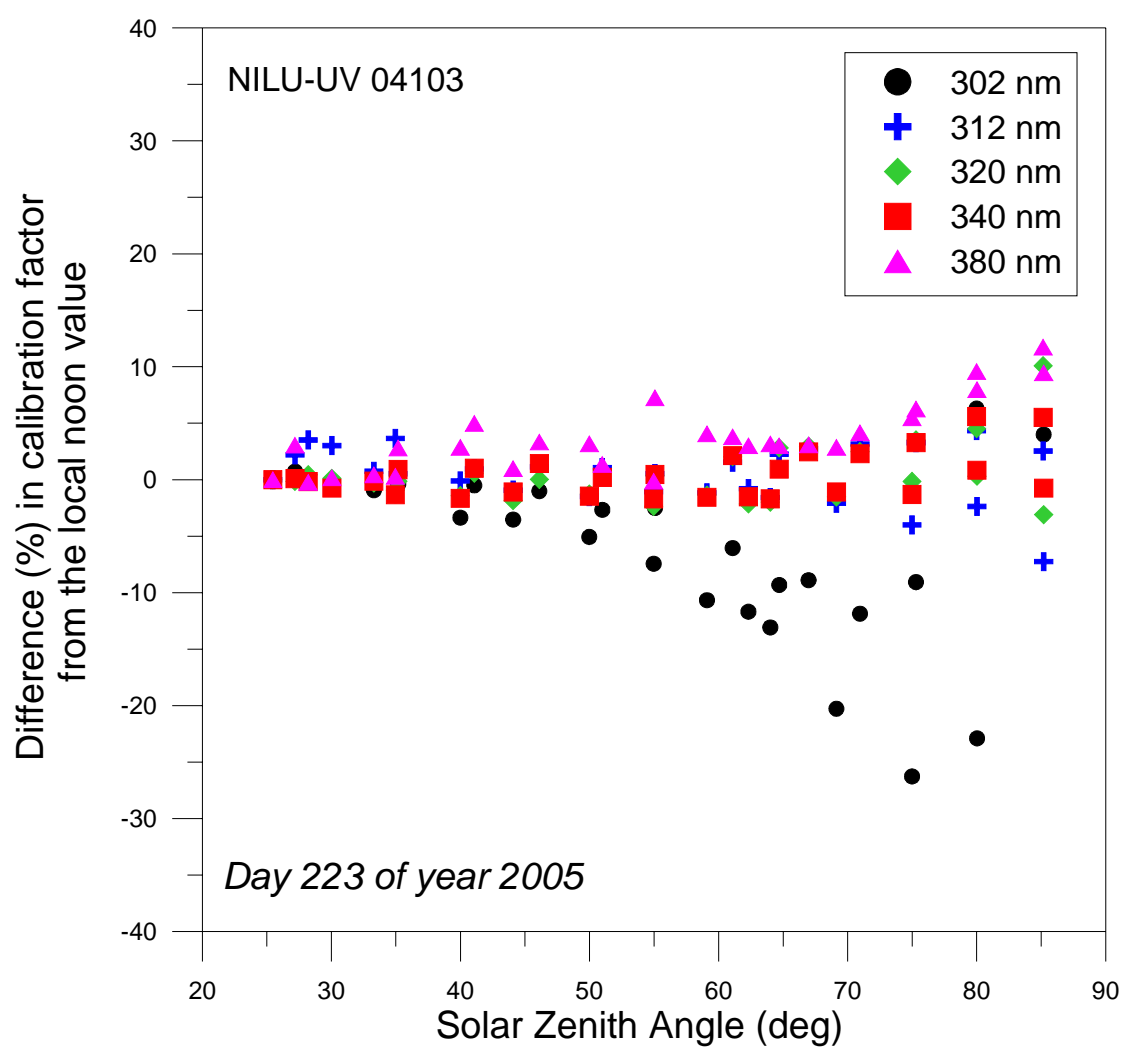

Figure 4. Difference (\%) in calibration factors from the local noon value as a function of solar zenith angle for NILU-UV 04103 for a summer day of 2005 .

The differences $(\%)$ in calibration factors from the local noon value as a function of solar zenith angle during a summer day of 2005 are presented at figure 4. For all channels (except $302 \mathrm{~nm}$ ) of NILU-UV 04103 (located at Thessaloniki), the percentage difference is less than 5\% (10\%) for solar zenith angle below $70(80)$ degrees. These differences could be partly attributed to the cosine error of the instruments, although there is an obvious divergence between morning and afternoon values at high solar zenith angles, possibly due to changes to the optical properties of the atmosphere (total ozone and aerosols) and to azimuthally dependent cosine response during the day ${ }^{10}$. The significantly increased differences for $302 \mathrm{~nm}$ (where the cosine error of radiometer and the uncertainty of spectral measurements are also higher) are indicative for the existence of a small shift in spectral response. 
The azimuth response of NILU-UV 04106 was tested by rotating the instrument during a cloud-free day with the Sun at $\sim 50^{\circ} \mathrm{SZA}$. After correcting for the change in irradiance due to SZA variation during the measurements $(\sim 10$ min duration), the azimuth response follows the pattern shown in Figure 5. For all channels the azimuth error is less than $\pm 1.5 \%$.

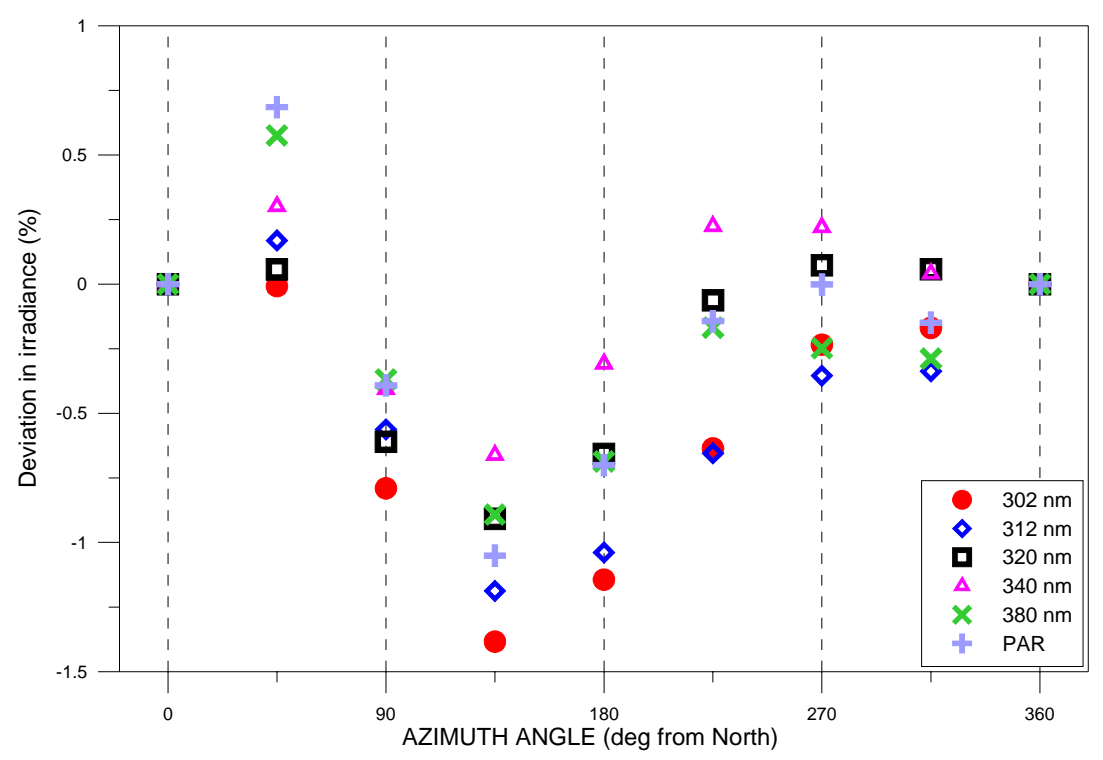

Figure 5. Azimuth response of NILU-UV 04106 multi-channel filter radiometer.

\subsection{Lamp measurements}

Possible changes in channel sensitivity of multi-channel filter radiometers could be examined with lamp test measurements. Two sets of three lamps (provided with a portable unit by the manufacturer) have been measured alternatively every month by NILU-UV 04103 and 04106, located at Thessaloniki. For each lamp, three measurements are performed, one with 04103 between two with 04106, in order to examine the stability of the lamp during the measurement time. In the great majority of cases, the difference between the two measurements with 04106 is less than $1 \%$. The whole procedure lasts less than 10 minutes and in all cases no difference in instrument internal temperature has been recorded. In all cases the measurements have been performed under fairly good weather conditions (light wind, no rain and typical Mediterranean temperature conditions). Lamp measurements of UV-B and UV-A irradiance performed by Brewer, confirmed their stability with time.

Concerning the drift of the channels, the two instruments show almost the same behavior. In figure 6 the mean measured difference $(\%)$ in lamp measurements from NILU-UV 04103 relative to the first measurement is presented. In cases that one lamp differed significantly from the other two, then it was discarded. The sensitivity of the first three channels (corresponding to 302, 312 and $320 \mathrm{~nm}$ nominal wavelengths) increased during the first half of year 2005. During the second part of year 2005 a significant decrease by $20 \%$ was examined, which was remained almost stable for 2006 . Severe downward drifts by $20 \%$ and $40 \%$ were occurred for 340 and $380 \mathrm{~nm}$ during the first year of operation. These drifts remain almost stable for these channels also during 2006. The magnitude of drifts in NILU-UV channel sensitivity is similar with results from other studies ${ }^{15,10}$.

\section{COMPARISON OF DATA PRODUCTS}

Calibration factors derived from lamp measurements applied to the raw counts of the instruments of the Greek UV network and the method of Dahlback ${ }^{12}$ used to derive total ozone and erythemal dose rate values. In this study, we present preliminary results from the comparison of network measurements with data from standard ultraviolet instruments. 


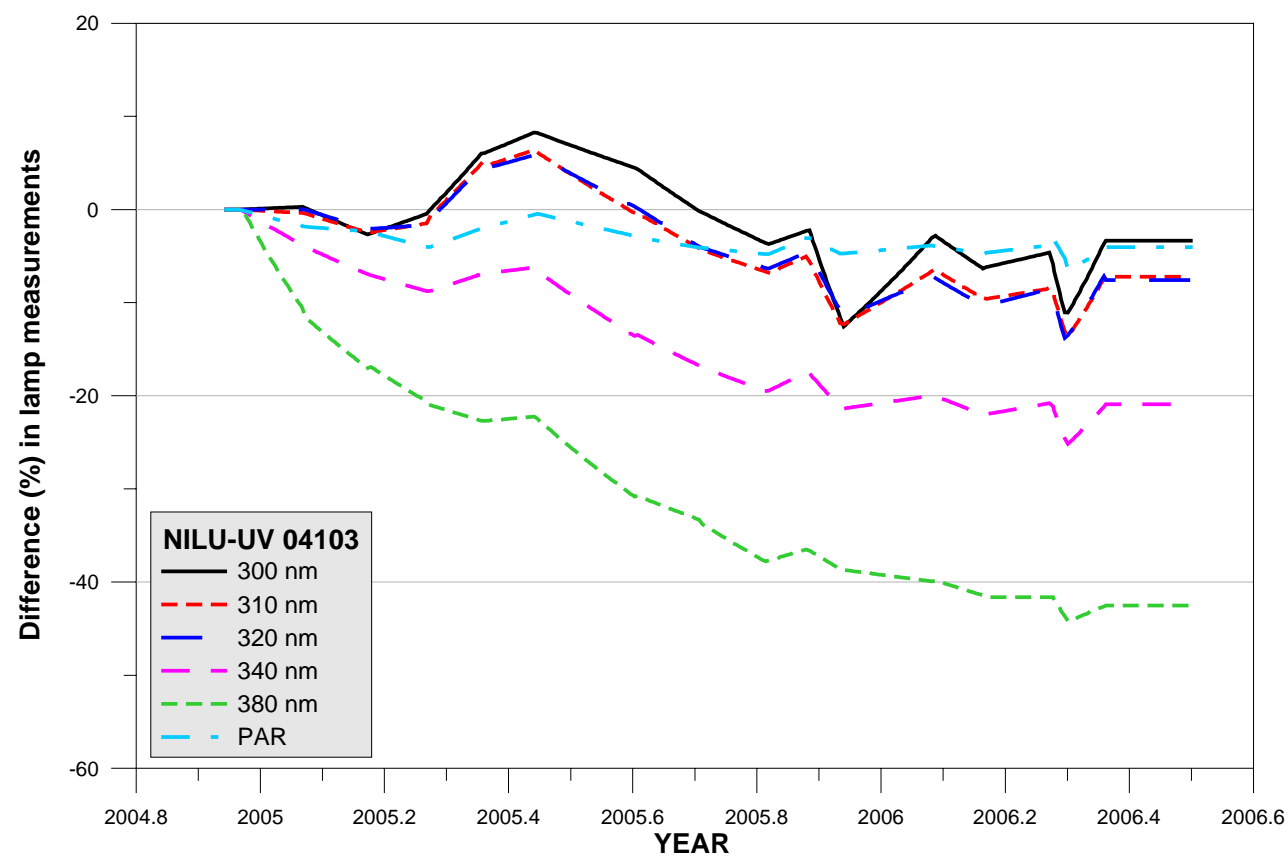

Figure 6. Variation in lamp measurements from NILU-UV 04103 with time

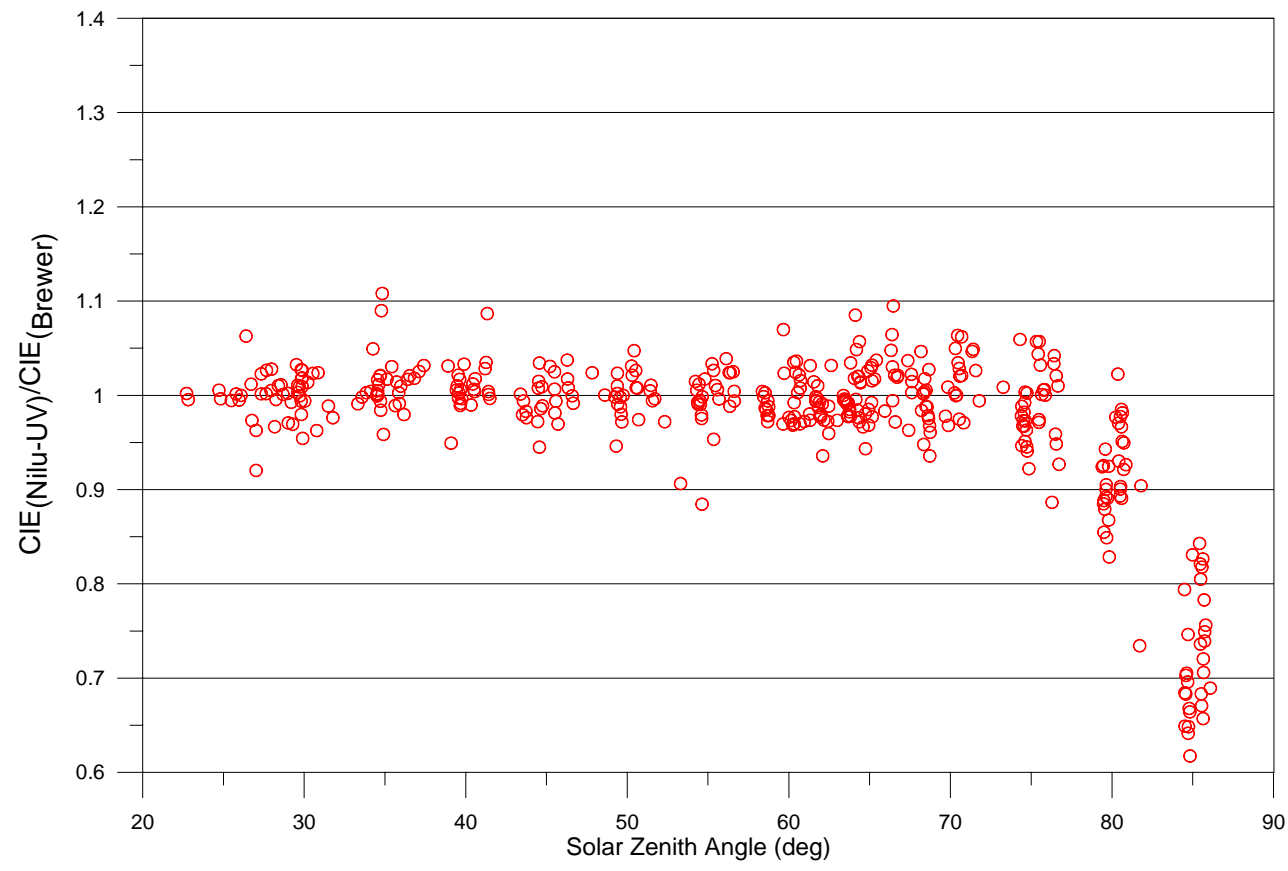

Figure 7. Comparison of CIE dose rates from NILU-UV 04103 and Brewer \#086, located at Thessaloniki.

Comparison results of NILU-UV 04103 erythemal dose rates (CIE) with Brewer measurements for twenty cloud-free days during 2004 and 2005 are presented in figure 7. Each ratio between values of the two instruments derived from an eight minutes average of UV dose rate from multi-channel filter radiometer divided with same quantity derived from 
one Brewer spectrum. For solar zenith angles below 75 degrees, the mean ratio is $1.00 \pm 0028$ and in all cases the difference between the two instruments is within $\pm 10 \%$. For higher solar zenith angles the difference increases significantly, mainly because of the possible uncertainty in NILU-UV spectral response and the use of non-cosine corrected data. Of course, the limited accuracy of the spectroradiometer and the effect the rapid change of solar zenith angle should not be neglected.

The comparison of the daily mean total ozone values from a northern (Thessaloniki, Greece) and a southern (Nicosia, Cyprus) site of the Greek UV network and the estimations from Ozone Monitoring Instrument (OMI) are presented in figure 8. For each day, the mean ozone value from NILU-UV instruments was calculated from one-minute averages for solar zenith angle below 70 degrees and cloud transmittance in the $340 \mathrm{~nm}$ channel higher than $50 \%$ and compared with the OMI measurement. The mean percentage differences at Thessaloniki and Nicosia are $1.3 \pm 2.3 \%$ and $2.0 \pm 2.0 \%$ respectively. Similar results have been calculated for the other sites of the network. Although further examination of the results is needed, the higher mean difference at Nicosia could be possibly attributed to the longer time period between lamp calibrations (once a year). In addition, the lower standard deviation from the mean could be related to the better weather conditions and higher solar zenith angle at the southern site.
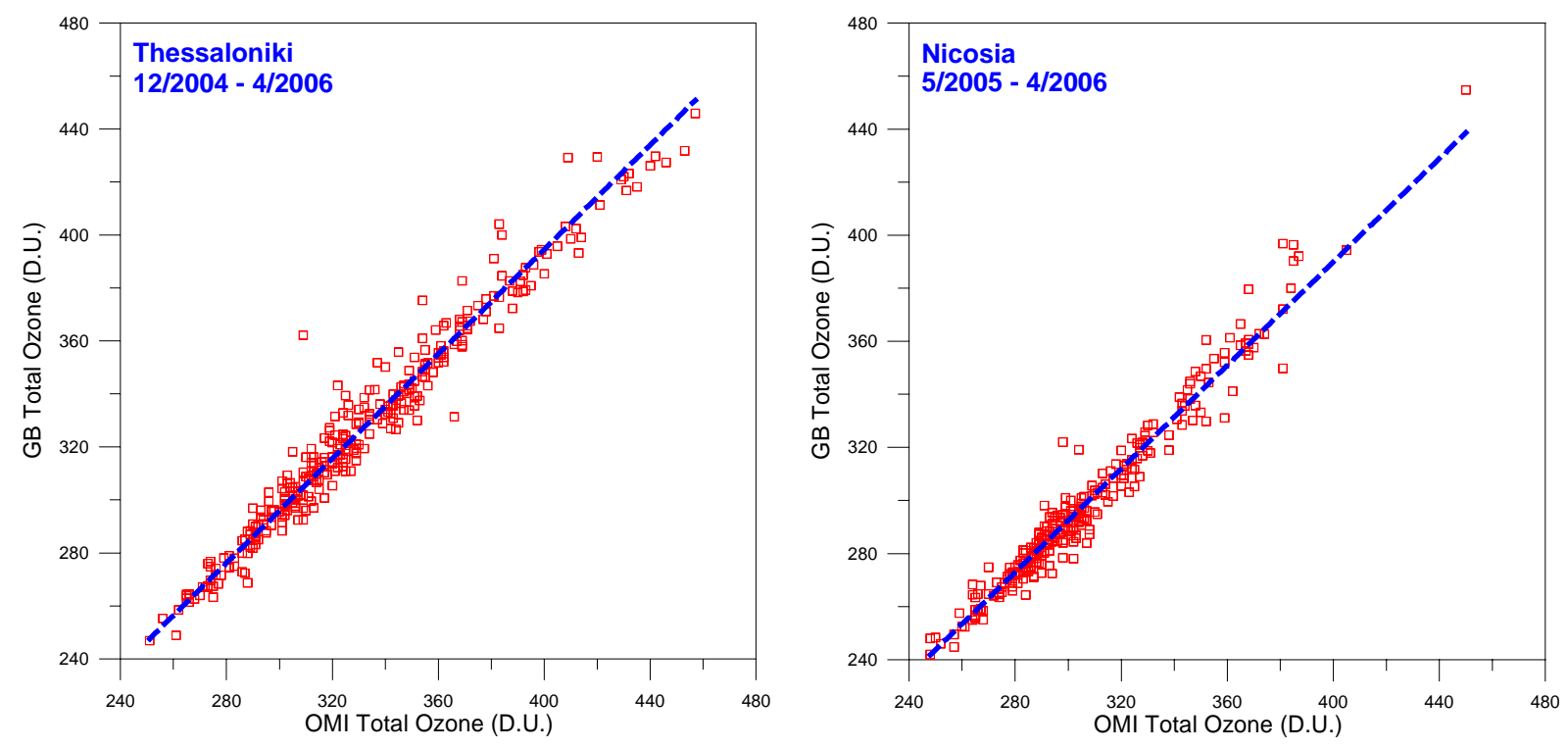

Figure 8. Comparison of the daily mean ozone values from ground-based (GB) stations at Thessaloniki and Nicosia with OMI estimates.

\section{CONCLUSIONS}

Preliminary results from quality assurance procedures during the pilot phase operation of the Greek UV network are presented in this study.

- The effect of the deviation in temperature from the stabilized internal value by few degrees is less than $1 \%$.

- The stability of the wavelength of maximum spectral response and the FWHM in the past three years was measured within $0.5 \mathrm{~nm}$. Further examination is needed on these findings, since it was shown from relevant studies that the corresponding errors in channel irradiances could be significant.

- The cosine error in channel irradiances could be considered negligible for $\mathrm{SZA}<60^{\circ}$, but increases significantly $\left(20 \%\right.$ for $\left.80^{\circ}\right)$ for the UV-B channels.

- The azimuth response of a NILU-UV for $\mathrm{SZA}=80^{\circ}$ was tested during a cloud-free day and the azimuth error was less than $1.5 \%$ for all channels 
- The drifts in channel sensitivity with time have been examined with the use of lamp test measurements. Downward drifts up to $40 \%$ have been shown during the first year of operation, especially at the UV-A channels.

- Calibration factors were calculated with the method described by Dahlback ${ }^{12}$. The observed differences during a day from the local noon value, could be indicative for errors in measurements of spectral response especially for UV-B channels.

- Calibration factors derived from lamp measurements were applied to non-cosine corrected raw counts of NILU-UV instruments and comparison of UV (CIE weighted) dose rates and daily mean ozone values with Brewer and OMI measurements were performed. According to results, the differences up 10\% in UV dose rates under cloud free conditions were observed for $\mathrm{SZA}<75^{\circ}$. For all sites, the mean difference in ozone measurements was less than $2 \%$ and with standard deviation was less than $2.5 \%$.

\section{ACKNOWLEDGEMENT}

This work was supported by the General Secretariat for Research and Technology, Ministy of Development, Greece, through Community Support Framework III

\section{REFERENCES}

1. Bais, A. F., C. S. Zerefos, C. Meleti, I. C. Ziomas, and K. Tourpali (1993), Spectral measurements of solar UVB radiation and its relations to total ozone, SO2 and clouds, J. Geophys. Res., 98(D3), 5199-5204

2. Kylling, A., Bais, A.F., Blumthaler, M., Schreder, J., Zerefos, C.S., Kosmidis, E., 1998. Effect of aerosols on solar UV irradiances during the photochemical activity and solar ultraviolet radiation campaign. Journal of Geophysical Research. 103, 26,051-26,060.

3. Zerefos C.S., C. Meleti, D.S. Balis, K. Tourpali and A.F. Bais, Quasi-biennial and longer term changes in clear sky UVB solar irradiance, Geophys. Res. Lett., 25, 4345-4348, 1998

4. Kazantzidis, A., Balis, D.S., Bais, A.F., Kazadzis, S., Galani, E., Kosmidis, E., Blumthaler, M., 2001. Comparison of model calculations with spectral UV measurements during the SUSPEN campaign: the effect of aerosols. Journal of Atmospheric Sciences 58, 1529-1539.

5. McKenzie, R. L., G. Seckmeyer, A. F. Bais, J. B. Kerr, and S. Madronich (2001), Satellite retrievals of erythemal UV dose compared with groundbased measurements at northern and southern midlatitudes, J. Geophys. Res., 106(D20), 24,051-24,062.

6. Fioletov, V. E., J. B. Kerr, D. I. Wardle, N. Krotkov, and J. R. Herman (2002), Comparison of Brewer ultraviolet irradiance measurements with total ozone mapping spectrometer satellite retrievals, Opt. Eng., 41(12), 3051-3061

7. Kazantzidis A., A. F. Bais, J. Grobner, J. R. Herman, S. Kazadzis, N. Krotkov, E. Kyro, P. N. den Outer, K. Garane, P. Gorts, K. Lakkala, C. Meleti, H. Slaper, R. B. Tax, T. Turunen, and C. S. Zerefos, Comparison of satellite-derived UV irradiances with ground-based measurements at four European stations, J. Geophys. Res., Vol. 111, D13207, doi:10.1029/2005JD006672, 2006

8. Johnsen, B., O. Mikkelborg, M. Hannevik, L. Nilsen, G. Saxebøl, and K. Blaasaas (2002), The Norwegian UVmonitoring program period 1995/96 to 2001, Stra ${ }^{\circ}$ levern Rapp. 2002:4, Norw. Radiat. Prot. Auth., Østera ${ }^{\circ}$ s.

9. Bernhard G., C.R. Booth, J.C. Ehramjian, Real-time ultraviolet and column ozone from multichannel ultraviolet radiometers deployed in the National Science Foundation's ultraviolet monitoring network, Optical Engineering 44(4), 041011 (April 2005)

10. Lakkala, K., et al. (2005), Quality assurance of the solar UV network in the Antarctic, J. Geophys. Res., 110, D15101, doi:10.1029/2004JD005584.

11. Koepke, P., and 23 co-authors, 1998, Comparison of models used for UV Index calculations, Photchem. Photobio., 67, pp 657-662

12. Dahlback, A. (1996), Measurements of biologically effective UV doses, total ozone abundances, and cloud effects with multichannel, moderate bandwidth filter instruments, Appl. Opt., 35(33), 6514-6521.

13. Høiskar, B., R. Haugen, T. Danielsen, A. Kylling, K. Edvardsen, A. Dahlback, B. Johnsen, M. Blumthaler, and J. Schreder (2003), Multichannel moderate-bandwidth filter instrument for measurement of the ozone-column amount, cloud transmittance, and ultraviolet dose rates, Appl. Opt., 42(18), 3472-3479. 
14. Slaper, H., H. A. J. M. Reinen, M. Blumthaler, M. Huber, and F. Kuik (1995), Comparing ground-level spectrally resolved solar UV measurements using various instruments: A technique resolving effects of wavelength shift and slit width, Geophys. Res. Lett., 22(20), 2721- 2724.

15. Norsang, G. (2004), Studies on solar ultraviolet radiation and ozone over the tibetan plateau, Ph.D. thesis, Univ. of Bergen, Bergen, Norway. 